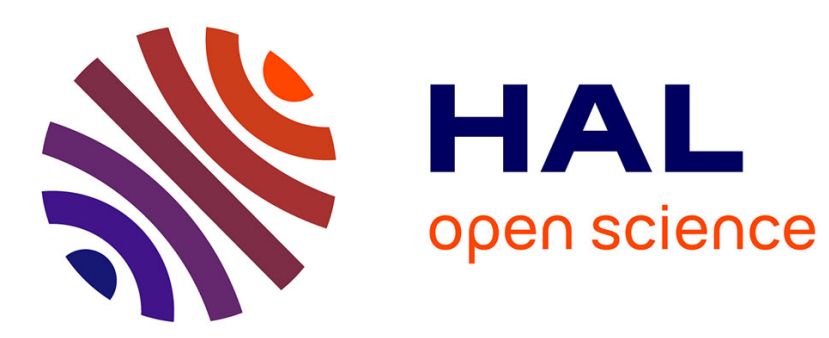

\title{
PLANARIZED INTERMETAL DIELECTRIC DEPOSITED BY DECR CVD
}

\author{
A. Tissier, J. Khallaayoune, A. Gerodolle, B. Huizing
}

\section{To cite this version:}

A. Tissier, J. Khallaayoune, A. Gerodolle, B. Huizing. PLANARIZED INTERMETAL DIELECTRIC DEPOSITED BY DECR CVD. Journal de Physique IV Proceedings, 1991, 02 (C2), pp.C2-437-C2444. 10.1051/jp4:1991253 . jpa-00249843

\section{HAL Id: jpa-00249843 https://hal.science/jpa-00249843}

Submitted on 1 Jan 1991

HAL is a multi-disciplinary open access archive for the deposit and dissemination of scientific research documents, whether they are published or not. The documents may come from teaching and research institutions in France or abroad, or from public or private research centers.
L'archive ouverte pluridisciplinaire HAL, est destinée au dépôt et à la diffusion de documents scientifiques de niveau recherche, publiés ou non, émanant des établissements d'enseignement et de recherche français ou étrangers, des laboratoires publics ou privés. 
Colloque C2, suppl. au Journal de Physique II, Vol. 1, septembre 1991

PLANARIZED INTERMETAL DIELECTRIC DEPOSITED BY DECR CVD

\author{
A. TISSIER, J. KHALLAAYOUNE, A. GERODOLLE and B. HUIZING(1) \\ CNET, chemin du Vieux Chêne, BP 98, F-38243 Meylan, France
}

\begin{abstract}
A low temperature DECR CVD $\mathrm{SiO}_{2}$ process has been developed using a multifactor multiresponse experimental design. The influence of the process parameters ( $\mathrm{SiH}_{4}$ and $\mathrm{O}_{2}$ flow rate, microwave power and $\mathrm{RF}$ bias voltage) on the film characteristics has been evaluated allowing deposition of high quality films. The dependency of the via filling efficiency and the planarization level with the RF bias voltage has been studied. In order to optimize the planarization process simulations were carried out using physically motivated models assuming that the phenomenon is described by the superposition of two independent processes: $\mathrm{SiO}_{2}$ deposition and sputter etching. Results on sputter etching simulation are given here.
\end{abstract}

\title{
1 - Introduction
}

With the rapid increase in the level of integration of semiconductor devices, the physical scaling of the device and the multilevel interconnect system has become more widespread.

Planarization of the dielectric layers, generally CVD oxide, is one of the crucial steps in these multilevel interconnection schemes. Techniques presently used include glass reflow $/ 1 /$, bias sputtered quartz and several processes involving successive deposition and etch back steps /2/. In the latter case, a number of processes include application of the material in the liquid the state by spin processing over CVD oxide films $/ 3 /$.

In fact, conventional deposition methods have difficulty in depositing CVD oxide conformally and in void-free filling high aspect ratio trenches. This means that there must be two components in the planarization process: firstly, filling of the spaces between the high aspect ratio metal lines with high quality oxide and, secondly smoothing of the topology.

A promising alternative is the Distributed Erectron Cyclotron Resonance (DECR) CVD which uses the ECR to generate a high density plasma that can deposit $\mathrm{SiO}_{2}$ films. Furthermore, during, or after the deposition, it is possible to RF bias the wafer so that ions present in the plasma can sputter etch the deposited films. This competition between deposition and sputter etching leads to planarization.

The aim of our work is to study the phenomena involved, the deposition and the sputter etching, in order to optimize the two interlevel dielectric requirements

(1) On leave from tU Mekelweg 4, P.O. BOx 5031, NL-2600 GA

Delft, The Netherlands 
previously mentioned : void-free via filling and surface planarization of the top film.

After a description of the DECR plasma deposition system, the results deduced from an experimental design conducted in order to optimize the $\mathrm{SiO}_{2}$ film qualities are reported. Then the model developed for the sputter etching is given and some examples comparing simulations with experiments are presented.

\section{2 - The DECR plasma deposition system}

The experiments were performed in the microwave multipolar plasma reactor shown schematically in Fig. 1. The microwave power $(f=2.45 \mathrm{GHz}$ ) is introduced by means of eight antenna distributed at the periphery of the reactor. The substrate is RF biased independently at $13.56 \mathrm{MHz}$. The electrical plasma characteristics $\mathrm{V}_{\mathrm{p}}$, plasma potential, $\mathrm{Te}$, electron temperature, and, $\mathrm{n}$, plasma density (or ion current density) were estimated by means of a Langmuir probe using an Ar plasma as a standard for characterization.

For a constant Ar pressure of $1 \mathrm{mT}$ Torr and various microwave input powers the main plasma characteristics are given in Table 1.

\section{Table 1. Electrical plasma characteristics}

\begin{tabular}{|l|c|c|c|}
\hline & $\mathbf{P}=500 \mathrm{~W}$ & $\mathbf{P}=1000 \mathrm{~W}$ & $\mathbf{P}=1500 \mathrm{~W}$ \\
\hline Te(eV) & 5.3 & 4.5 & 3.5 \\
\hline $\mathbf{n}(\mathrm{cm}-3)$ & 1011 & 1.61011 & 1.91011 \\
\hline
\end{tabular}

The temperature of the substrate holder is regulated by Joule effect heating and water cooling. It was maintained at $60{ }^{\circ} \mathrm{C}$ during the deposition step in our experiments. Nevertheless, no particular system was used in order to clamp the wafer onto the substrate and consequently the wafer temperature may have increased due to ion bombardment. The maximum temperature was estimated to be equal to $200{ }^{\circ} \mathrm{C}$, taking into account actual wafer temperature measurements made in a similar reactor $/ 6 /$.

The reactant gas mixture was silane and oxygen. This oxidant was chosen, instead of $\mathrm{N}_{2} \mathrm{O}$ or NO commonly used in PECVD $\mathrm{SiO}_{2}$ deposition, in order to eliminate problems resulting from nitrogen incorporation in the deposited film. On the other hand, it is more difficult to control this process because direct reaction between $\mathrm{SiH}_{4}$ and $\mathrm{O}_{2}$ may occur.

In the original reactor, silane was directly introduced into the dense plasma, but this produced DECR films with very rough surfaces. In consequence the position and geometry of the silane injector was adjusted in order to obtain a uniform deposit of $\mathrm{SiO}_{2}$ films. As shown in Fig. 1, the annular $\mathrm{SiH}_{4}$ injector is in the lower region in order to reduce $\mathrm{SiH}_{4}$ excitation by the microwave plasma. 


\section{3 - Deposition characteristics and film quality :}

A systematic multifactor multiresponse study of the DECR CVD $\mathrm{SiO}_{2}$ was conducted in order to evaluate the effects of the process parameters on $\mathrm{SiO}_{2}$ film properties. The four independent factors, at three levels, selected for the quadratic design experiments are displayed in Table 2 with the test intervals.

\section{Table. 2 Factors and intervals investigated}

\begin{tabular}{|l|c|}
\hline \multicolumn{1}{|c|}{ Parameters: } & Intervals \\
\hline Silane flow (Sccm) & 4 to 10 \\
\hline Oxygen flow (Sccm) & 4 to 80 \\
\hline Microwave Power (Watt) & 500 to 1200 \\
\hline RF bias (Volt) & -200 to 0 \\
\hline
\end{tabular}

It should be noted that it is not possible with the equipment used to keep the pressure constant. For the experiments presented here the working pressure, prior to plasma creation, ranged from 0.5 to $2.5 \mathrm{~m}$ Torr. Under these conditions the $\mathrm{SiH}_{4}$ and $\mathrm{O}_{2}$ partial pressures ranged from 0.08 to 0.22 mTorr and from 0.18 to 1.4 mTorr respectively.

Using the Response Surface Modeling (RSM) method empirical models were deduced for the properties of the deposited films. Two kinds of properties were investigated : i) process properties, namely deposition rate and thickness uniformity and ii) physico-chemical properties : stress, refractive index, wet etch rate and bonding characteristics deduced from FTIR Spectroscopy.

Depending on the deposition rate, the deposition time was adjusted accordingly to give $\mathrm{SiO}_{2}$ thickness of 0.5 to $0.8 \mu \mathrm{m}$ in order to achieve high accuracy responses. Nevertheless, for the refractive index determination, a second run was performed using the same parameter values but with a resulting 0.12 to $0.14 \mu \mathrm{SiO}_{2}$ thickness.

A detailed interpretation of these experiments will be published elsewhere $/ 7 /$ but the main results deduced from this study are given below.

Deposition rate: The regression analysis of the experimental results shows that the deposition rate - ranging from 60 to $400 \AA / \mathrm{min}$ - is significantly affected by three factors : silane and oxygen partial pressures and RF bias voltage, the strongest influence being the silane partial pressure. It should be noted that surprisingly the deposition rate is only slightly affected by the microwave power. These results suggest that the deposition rate is limited by the silane adsorption on the wafer. An increase in the silane flow would lead to an increase in the deposition rate. Using coefficients of the regression it can be interpolated that a $20 \mathrm{sccm} \mathrm{SiH} 4$ flow rate would lead to a deposition rate equal to $600 \AA / \mathrm{min}$. 
Thickness Uniformity : The silicon oxide films thickness uniformity, U, is defined by :

$$
\mathrm{U}=+/-3 * \mathrm{SD} / \mathrm{MNTH}
$$

where MNTH and SD are the mean value and the standard deviation of the thickness determined by reflectivity measurement at 33 points.

The experimental results show that the oxygen flow and microwave power and RF bias voltage are the factors with the strongest influence. An improvement in uniformity is achieved by increasing these three factors. A value lower than $3 \%$ can be obtained.

Stress : The stress of the deposited $\mathrm{SiO}_{2}$ films, always tensile and ranging from 50 to $200 \mathrm{MPascal}$, is strongly affected by the silane and oxygen flow rates.

Refractive index : It was not possible to determine by ellipsometry the refractive index of the films deposited with silane gas flow rate superior to that of oxygen. For the experiments reported the refractive index ranged between 1.46 and 1.47 for more than $90 \%$ of the films investigated.

FTIR Spectroscopy : FTIR spectroscopy has been widely used for checking the purity of the films and for the determining the bonding characteristics of the $\mathrm{SiO}_{2}$ films. Parameters extracted from the absorption spectra can provide some information on the oxide stoichiometry $/ 8 /$.

In this study two parameters were used :

i) $\mathrm{R}$ defined as the ratio of intensities of the two components of the broad stretching band near to $1100 \mathrm{~cm}^{-1}$ (shoulder and sharp peak)

ii) $\Delta v$, the full width at half maximum of the sharp band.

From these FTIR experiments it can be deduced that more than $50 \%$ of the films produced showed no sign of Si-OH and SI-H bonds. Secondly, the strongest influence on $\Delta v$ is the RF bias voltage. Increasing the RF bias voltage allows deposition of DECR CVD silicon oxide films with a bonding structure similar to that of thermal films.

Finally, on the basis of this experimental design analysis, we establish an optimum set of process parameters, with a large process window leading to high quality films. The process parameters are given below.

Table 3. Deposition conditions for high quality $\mathrm{DECR} C \mathrm{CVD} \mathrm{SiO}_{2}$

\begin{tabular}{|l|c|}
\hline \multicolumn{1}{|c|}{ Parameters: } & 10 \\
\hline Silane flow (Sccm) & 60 \\
\hline Oxygen flow (Sccm) & 1000 \\
\hline Microwave Power (Watt) & -100 \\
\hline RF bias (Volt) & \\
\hline
\end{tabular}


The characteristics of the films deposited using these process conditions are summarised in the next table.

Table 4. Properties of $\mathrm{DECR}$ CVD $\mathrm{SiO}_{2}$ films compared to thermal
$\mathrm{SiO}_{2}$

\begin{tabular}{|c|c|c|}
\hline & $\overline{\text { DECR } \mathrm{SiO}_{2}}$ & Thermal $\mathrm{SiO}_{2}$ \\
\hline Deposition rate $(\hat{\mathrm{A}} / \mathrm{min})$ & 330 & \\
\hline Uniformity (\%) & $+1-4 \%$ & $+/-1 \%$ \\
\hline Etch rate in HF (*) & 1.8 & 1 \\
\hline$\Delta \mathrm{v}\left(\mathrm{cm}^{-1}\right)$ & $82+1-5$ & $75+/-1$ \\
\hline Stoichiometry $(* *)$ & $2.1+/-0.1$ & $2.0+/-.0 .05$ \\
\hline
\end{tabular}

(*) Normalised to thermal oxide

(**) Deduced by RBS measurement

\section{4 - Via filling and planarization aspect}

This section concerns the study of the gap-filling efficiency of the DECR CVD silicon oxide films as a function of the RF bias voltage. For this study $\mathrm{SiO}_{2}$ films were deposited, using the process conditions previously described, on test wafers having $1.5 \mu \mathrm{m}$ deep silicon trenches with aspect ratios of up to 2.5 . The gapfilling efficiency is evaluated by ARmax defined as the highest value of the aspect ratio at which the trench is void-free filled. The evolution of the gap-filling efficiency, ARmax, is plotted in Fig. 2 The films deposited without RF bias are comparable to those of more classical PECVD. With increasing RF bias voltage the gap-filling ability increases and trenches with aspect ratios as high as 2.5 can be filled without any voids.

Note that for an RF bias voltage superior to $200 \mathrm{~V}$ the sidewall of the underlying structure is slightly sputter etched. Fig 3 shows examples of such high aspect ratio void-free fillings. The perfect planarization level achieved for the $1.5 \mu \mathrm{m}$ deep trenches is shown in Fig.4.

All the results presented here show that the DECR CVD silicon oxide is able to fulfil the requirements previously mentioned: high quality $\mathrm{SiO}_{2}$ films, void-free high aspect ratio gap-filling and surface planarization. The two last requirements are strongly correlated with the density of underlying features and, consequently, process parameters have to be carefully chosen.. Significant benefit can be extracted by the use of the simulation. The next section gives the results of the simulation work initiated for that purpose.

\section{5 - Simulation}

The capability of simulating coupled deposition and sputter etching steps has been added to the process simulator TITAN $/ 9 /$. An efficient algorithm /10/ is used, 
which avoids instability and allows the geometrical shapes to be determined accurately. The principle is that the characteristic locus curve (Figure 5) deduced from the sputter etch yield versus angle curve $Y(\theta)$ (Figure 6) is used to determine the transformation at each time step of the concave and convex corners, and in particular the passage from abrupt corners to curved surfaces.

A polynomial approximation is used for the sputter etch yield curve $Y(\theta)$. The deposition rate and sputter etch yield curve coefficients corresponding to given process conditions are input parameters for the simulation. The use of the optimisation tool, PROFILE /10/, allows the automatic calibration of these data for given process conditions, by adjusting simulation results on a set of experimental results. As an example, Figure 7 compares experimental and simulated profiles of an etching process, after calibration of the sputter etch yield versus angle curve. It should be noted that the simulation produces the slight curvature experimentally observed in the lower part of the profile.

The program can then be used to predict the change during the process time of any initial geometrical shape. As an example, Figure 8 shows that two steps, with different slopes, result, after a given etching time, in the same final shape. Finally after coupling with the deposition model, filling of contact holes (Figure 9) can also be predicted, and this is in good agreement with the experimental behaviour.

\section{References}

(/1/ W. Kern and R. Smeltzer, Solid State Technology, (1985) 171).

(/2/ S. Mehta and C. Sharma, Proceedings of the 6th IEEE VLSI Multilevel Interconnection Conference, (1989) 80).

(/3/ N. Parekh, A. Butler, W. Doedel, W. Heesters and L. Forester Proceedings of the 6th IEEE VLSI Multilevel Interconnection Conference, (1989) 447).

(/4/ K. Machida and H. Oikawa,J.Vac.Sci.Technol. B, Vol. 4, No. 4, (1986) 818).

(/5/ F. Plais,B. Agius, F. Abel, J. Seijka, M. Puech and P. Almost, Ext. Abs. Electrochemical Society Meeting , PV 89-7 (1989) 285).

(/6/ A. Durandet, O. Joubert and J. Pelletier, J.Appl. Phys. 68 (8), (1990) 3862).

(/7/ J.Khallaayoune Phd Thesis in progress).

(/8/ P. G. Pai, S. Chao, and Y. Takagi, J. Vac. Sci.Technol. A 4, (1986) 689).

(/9/ A. Gérodolle, C. Corbex, A. Poncet, T. Pédron, S. Martin, "TITAN 5, a two-dimensional process and device simulator", in W. Crans, editor, "Software Tools for Process, Device and Circuit Modelling", Boole Press, July (1989)).

(/10/ M. J. Nobes, I. V. Kartadjiev, G. Carter and R. Smith, J. Appl Phys 20 (1987) 870-879).

(/11/ G. J. L. Ouwerling, F. van Rijs, B. F. P. Jansen and W. Crans, "Inverse modelling with the PROFILE optimization driver", in W. Crans,editor, "Software Tools for Process, Device and Circuit Modelling", Boole Press, July (1989)). 


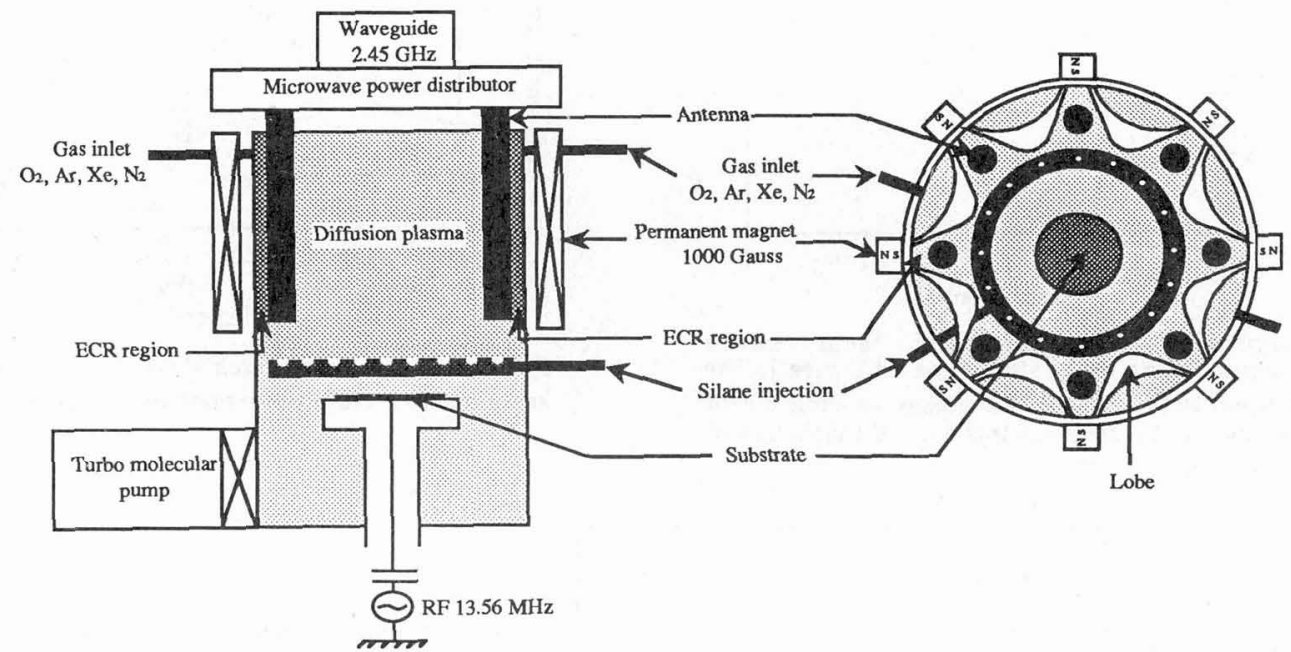

Fig. 1: Schematic of the DECR microwave plasma deposition system

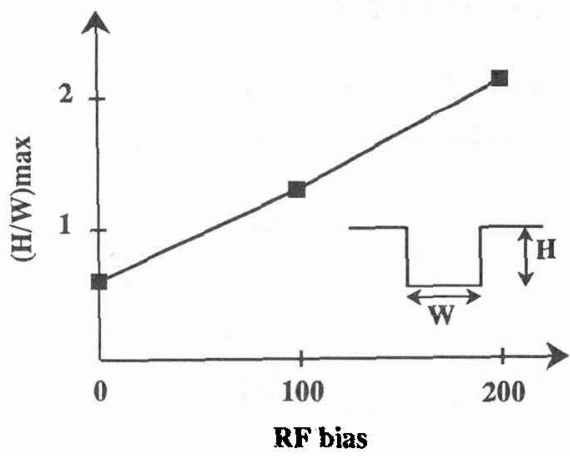

Fig. 2: RF bias voltage dependance of gap filling efficiency

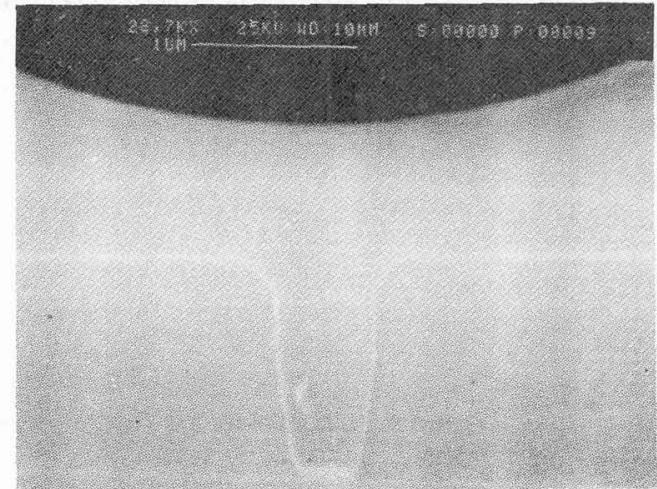

Fig.3: SEM micrographs of high aspect ratio via filling

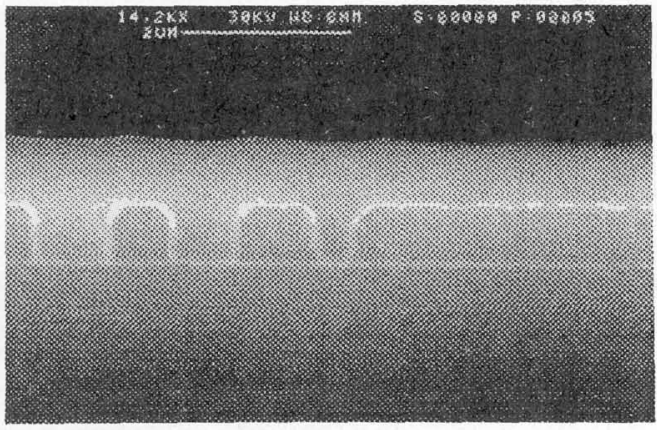

Fig.4: SEM micrographs of DECR planar deposition 


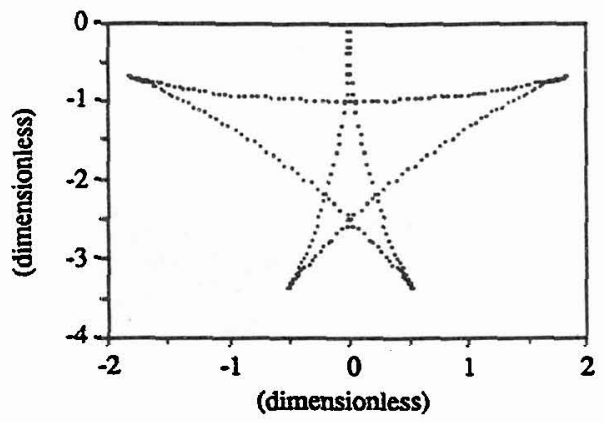

Figure 5. Characteristic locus curve corresponding to the simulation of Figure 7. The tangent to the curve which makes the angle $\theta$ with the horizontal direction intersects the vertical axis at the ordinate $\cdot Y(\theta)$.
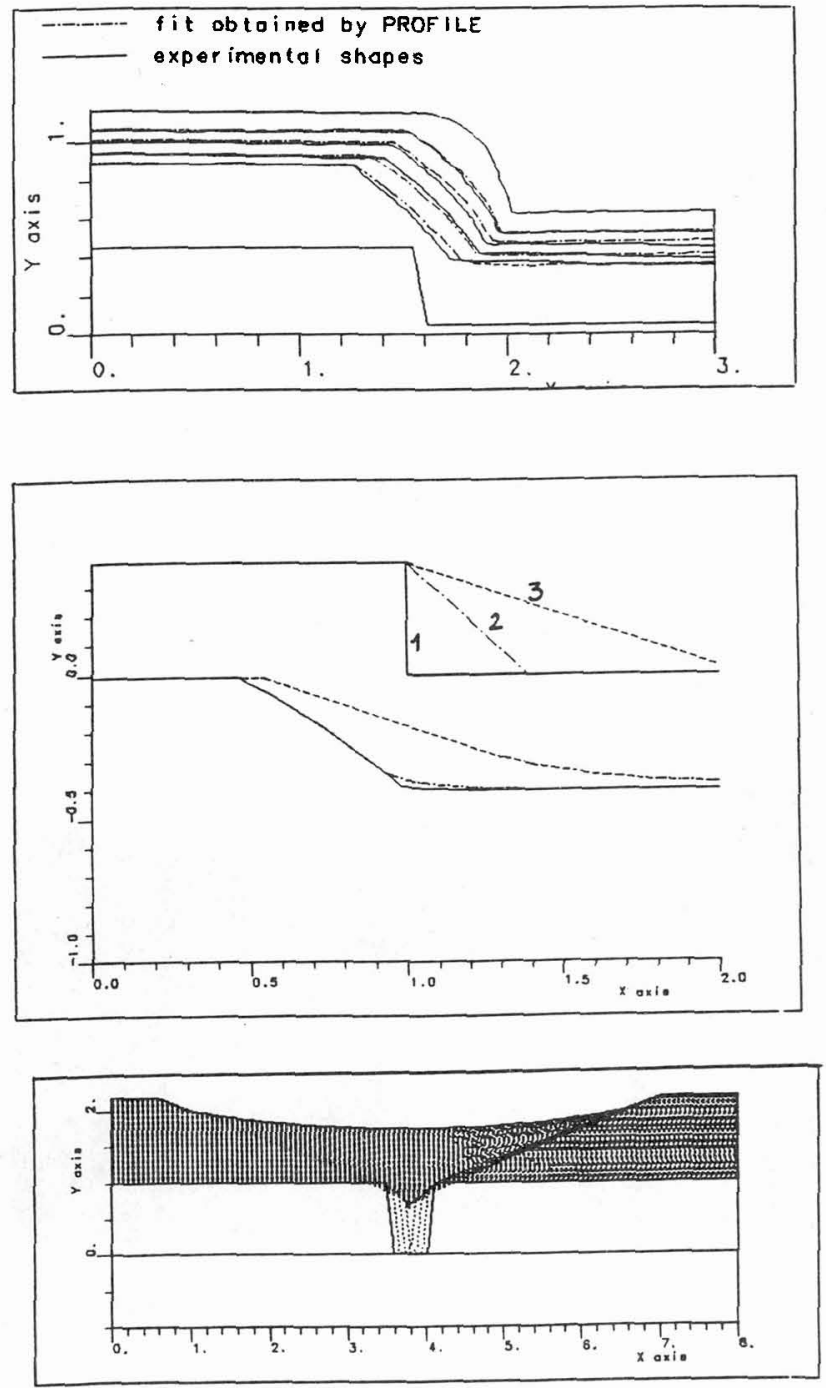

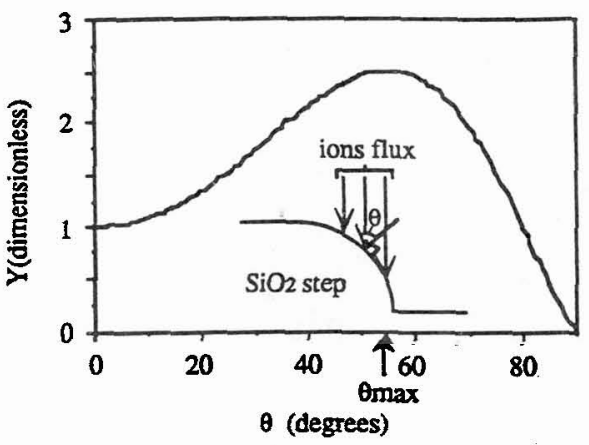

Figure 6. Argon sputter etch yield versus incidence angle curve $(Y(\theta))$ corresponding to Figure 5.

Figure 7. Comparison between simulated (thin lines) and experimental (thick lines) profiles after 4, 6, 8 and 10 minutes of Ar sputter etching.

Figure 8. Argon sputter etch simulation:

- sputter etch leads to identical profiles for steps with $\theta>\theta \max (1$ and 2 )

- sputter etch leads to different profile for $\theta<\theta \max (\mathbf{3})$.

Figure 9. Simulation of DECR CVD $\mathrm{SLO}_{2}$ via filling 